\title{
Potentiometric Studies on Complexation Equilibria between Dimethyltin (IV) and Dioctyltin (IV) Cations with N-N Donor Ligands
}

\author{
Pratibha Paliwal (Bhatele)
}

Department of Science, Kamla Nehru College For Women, Phagwara. Punjab, India

\begin{abstract}
The interaction of dimethyltin [DMT] (IV) and dioctyltin [DOT] (IV) cations with 2,2'-bipyridyl and 1,10-phenanthroline were performed potentiometrically for 1:1 systems in $10 \%$ alcohol medium at three ionic strengths $(\mu=0.05,0.10,0.15 M)$ and at three different temperatures $20^{\circ} \mathrm{C}, 30^{\circ} \mathrm{C}, 40^{\circ} \mathrm{C}$. The experimental data are subjected to computational analysis in order to evaluate thermodynamic formation constants $\left[M L, M L(O H)\right.$ and $\left.M L(O H)_{2}\right]$ and other thermodynamic parameters $\left(\Delta G^{\circ}, \Delta H^{\circ}\right.$ and $\left.\Delta S^{\circ}\right) . A$ stability constant of generalized species (SCOGS) computer program was employed for computation. The concentration distribution of the various complex species in solution has been evaluated as a function of $\mathrm{pH}$ and is presented in the form of speciation curves. The studies intimate that 2,2'-bipyridyl formed complexes of low stability than 1,10-phenanthroline. This is attributed to the difference in ring structure of two ligands.
\end{abstract}

Keywords: DMT (IV), DOT (IV), Thermodynamic formation constants, SCOGS

\section{Introduction}

The importance of diorganotin complexes in the field of biology, medicine, environment and industry is of great concern. Literature survey reveals that considerable attempts have been made to understand the reactivity of diorganotin (IV) cations towards N, P and O donor ligands [1]-[5].

Many complexes of the type $\mathrm{R}_{2} \mathrm{SnX} \mathrm{X}_{2}(\mathrm{~N}-\mathrm{N})$ have been synthesized and tested [6], in which the N-N ligands are symmetric N,N-chelating agents such as bipyridine type ligands [7] or asymmetric ones such as 8-aminoquinoline [8]-[10]. Several research papers have been published by Pettinari et al. on tin (IV) and organotin (IV) complexes containing mono or bidentate N-donor ligands [11]-[16].

The studies on complexation equilibria and structures of dimethyltin (IV) with N-methyliminodiacetate, pyridine-2,6dicarboxylate, ethylenediamine-N,N'-diacetate and ethylenediamine-N,N,N',N'-tetraacetate are available in literature [17].

The biological activity of organotin complexes is believed to be independent on the structure of molecule and coordination number of metal are reported in recent past [18]. For compounds $\left[\mathrm{SnR}_{2} \mathrm{X}_{2}(\mathrm{LL})\right]$, where $\mathrm{LL}$ is an $\mathrm{N}, \mathrm{N}-$ bidentate ligand, antitumour activity depends on the $\mathrm{Sn}-\mathrm{N}$ distances $\left(>2.39\right.$ and $\left.<2.39 \mathrm{~A}^{\circ}\right)$ for the active and inactive compounds, respectively [19]-[20], which suggests that dissociation of the ligand is a significant step in their mechanism of action.

In this paper we elaborate the subject and develop further understanding regarding the interaction of organotin (IV) cation with N-N donor ligands in order to calculate stability constants of the complexes and other thermodynamic parameters.

\section{Experimental}

\subsection{Solution}

All the reagents used were of analytical grade and prepared in deionised water. Solution of ligands viz. 2,2'-bipyridyl and 1,10-phenanthroline were prepared by dissolving accurately weighed amounts in double distilled water to get $0.01 \mathrm{M}$ solution of each. They were used as their diprotonated form by adding two equivalent of acid in the course of titration. Solutions of metal (0.01M) DMT(IV) dichloride and DOT(IV) dichloride (Aldrich) were prepared in distilled ethanol.

\subsection{Instrument}

An Elico digital pH-meter model LI-127 with ATC probe and combined electrode type (CL-51B-Glass body; range 0$14 \mathrm{pH}$ unit; $0-100^{\circ} \mathrm{c}$ automatic/manual) with accuracy \pm 0.01 was used for $\mathrm{pH}$ measurement. The $\mathrm{pH}$ meter was calibrated with aqueous buffers ( $\mathrm{pH} 4.0$ and 9.20) before and after titration.

\subsection{Experimental Condition and Titrations}

Three sets of titration mixtures (1,2 and 3) were prepared at three different ionic strengths $(\mu=0.05 \mathrm{M}, 0.10 \mathrm{M}$ and $0.15 \mathrm{M})$ maintained by $\mathrm{NaNO}_{3}$, keeping the total volume $50 \mathrm{ml}$. All the titration mixtures were maintained with the ratio of $10 \%$ alcohol and $90 \%$ water.The mixtures were titrared individually against $0.10 \mathrm{M} \mathrm{NaOH}$ solution at three different temperatures $\left(20 \pm 1^{\circ} \mathrm{C}, 30 \pm 1^{\circ} \mathrm{C}\right.$ and $\left.40 \pm 1^{\circ} \mathrm{C}\right)$ and thus three titration curves are obtained.Temperature was maintained by Siskin Julabo, thermostat model V-12B. These titration mixtures are :

(i) Acid titration: $\mathrm{HNO}_{3}\left(2.0 \times 10^{-3} \mathrm{M}\right)$

(ii) Ligand titration: $\mathrm{HNO}_{3}\left(2.0 \times 10^{-3} \mathrm{M}\right)+$ ligand $\left(1.0^{\times} 10^{-3} \mathrm{M}\right)$ 


\section{International Journal of Science and Research (IJSR) \\ ISSN (Online): 2319-7064}

Index Copernicus Value (2013): 6.14 | Impact Factor (2014): 5.611

(iii) Metal : Ligand (1:1) titration : $\mathrm{HNO}_{3}\left(2.0^{\times} 10^{-3} \mathrm{M}\right)+$ ligand $\left(1.0^{\times} 10^{-3} \mathrm{M}\right)+\operatorname{Metal}\left(1.0^{\times} 10^{-3} \mathrm{M}\right)$

\section{Results and Discussion}

\subsection{Titration Curves}

For each set of experiments, $\mathrm{pH}$ was plotted against volume of titrant added and from these curves, moles of alkali required per mole of metal/ligand ('a') was determined. These titration curves were obtained by plotting $\mathrm{pH}$ vs. ' $\mathrm{a}$ '. Representative titration curves are given in figures 1 and 2 .

An examination of the ligand titration curves for 2,2'bipyridyl (figure 1, curve 1) and 1,10-phenanthroline (figure 2 , curve 1) show a buffer region in $\mathrm{pH}$ range $2.8-5.5$ thereby indicting the liberation of two protons in overlapping steps. The values of dissociation constants obtained for the ligands are in good agreement with the literature values [21].

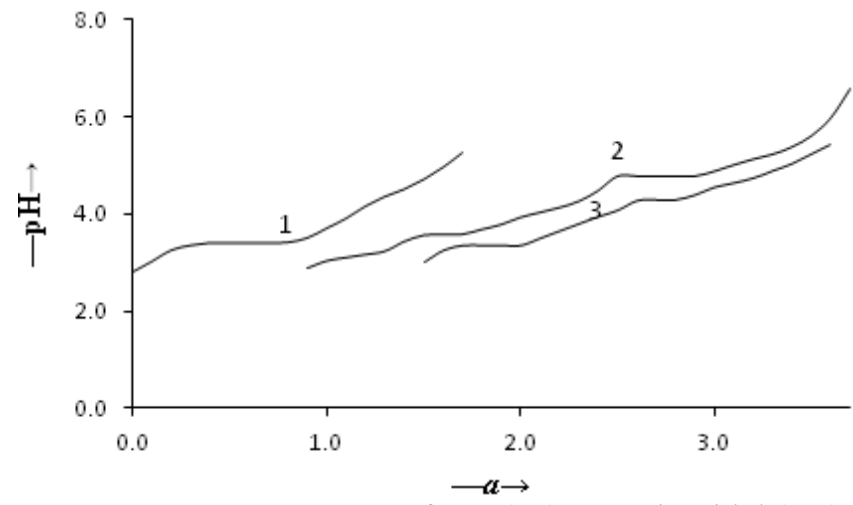

Figure 1: pH vs. ' $a$ ' Curves for M(IV)-2,2'-Bipyridyl (1:1) System at $30 \pm 1^{\circ} \mathrm{C}\left[\mu=0.10 \mathrm{M}\left(\mathrm{NaNO}_{3}\right)\right]$

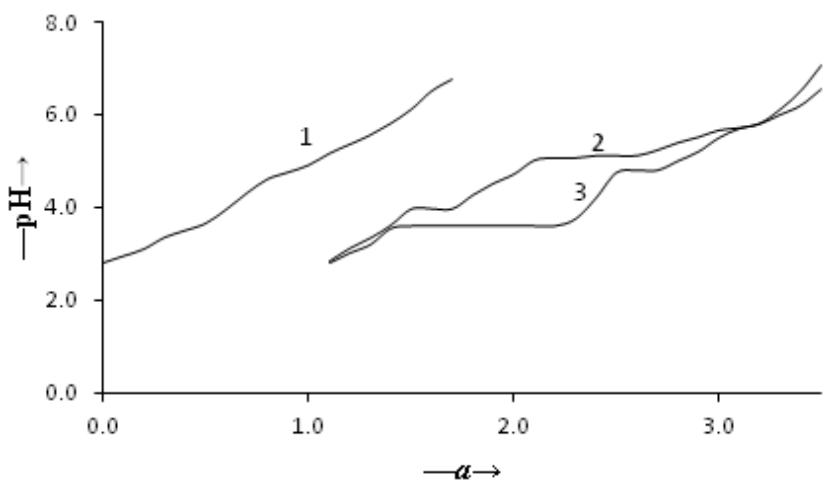

Figure 2: $\mathrm{pH}$ vs. ' $a$ ' Curves for M(IV)-1,10-Phenanthroline (1:1) System at $30 \pm 1^{\circ} \mathrm{C}\left[\mu=0.10 \mathrm{M}\left(\mathrm{NaNO}_{3}\right)\right]$

In figures 1 and 2

Curve 1- represents Ligand titration curve

Curve 2- represents DMT (IV) Ligand titration curve

Curve 3- represents DOT(IV) Ligand titration curve

The metal-ligand titration curves (curves 2 and 3 ) in figures 1 and 2 suggest the formation of ML species in $\mathrm{pH}$ range 2.5 - 3.7 at $a \leq 2$. The equilibria for various system can be represented as follows :

$$
\begin{aligned}
& \mathrm{M}+\mathrm{L} \\
& 0 \leq a \leq 2 \\
& \begin{array}{ll}
\mathrm{ML}+\mathrm{OH} \quad \stackrel{2 \leq a \leq 3}{\rightleftharpoons} \underset{\mathrm{ML}(\mathrm{OH})}{\rightleftharpoons} \mathrm{ML}(\mathrm{OH})+\mathrm{OH} \stackrel{\mathrm{ML}}{\rightleftharpoons} \mathrm{MLH})
\end{array}
\end{aligned}
$$

(Charges have been omitted for the sake of simplicity).

Algebraic method of Martell and Chaberek as modified by Dey et al. has been used to obtain the values of proton and metal equilibrium constants [22]-[26]. The calculation of stability constants of metal ligand hydroxy species is done by applying method developed by M. Chandra [27]. The values of protonation constants for various ligands and the formation constants of metal-ligand complexes are tabulated in tables $1-3$. Values of formation constants were plotted against $\sqrt{\mu}$ and extrapolated to zero ionic strength, to calculate thermodynamic stability constants. The considerably high values of formation constants for ML species observed from these tables support that the complex formed is thermodynamically stable. At higher $\mathrm{pH}$ range hydroxo complex appear to be the major species. The logarithmic values of equilibrium constants for various proton-ligand and metal-ligand systems were refined by using the SCOGS computer programme [28]-[30]. These data was used to obtain the speciation curves. Analysis of these curves is discussed here under:

Distribution curves of DMT (IV)- 2,2'-bipyridyl and DOT (IV)- 2,2'-bipyridyl system show a very low percentage of free metal ion (curve 1) in the initial stage followed by the continuous decrease. The formation of ML species is observed from initial $\mathrm{pH}$ and the percentage is significantly high. The percentage of ML species in DMT (IV)-2,2'bipyridyl system is about $58 \%$ which is low as compared to that observed in case of DOT (IV) - 2,2'-bipyridyl system (i.e. $85 \%$ ). With the increasing $\mathrm{pH}$ the percentage of ML species decreases continuously and attains the minima at $\mathrm{pH} \approx$ 4.8. The speciation of hydroxo species is presented by curves 3 and 4 in figures 3 and 4 . The monohydroxy species is formed in negligible amount and the dihydroxy species $\mathrm{ML}(\mathrm{OH})_{2}$ is observed to be the major species in the distribution profile.

Curve 1 shows the concentration of free metal ion to be nearly $42 \%$ in initial stage in case of DMT(IV)- 1,10 phenanthroline system whereas it is quite low in DOT(IV)1,10-phenanthroline system. The formation of ML species (curve 2) occurs from the initial $\mathrm{pH}$ and the reaches the maximum percentage $(\approx 60 \%)$ at about $\mathrm{pH} 3.0$ in the former system whereas the concentration of ML species is about $75 \%$ in case of latter system. In the higher $\mathrm{pH}$ range formation of monohydroxy complex and dihydroxy complex is observed, depicted by curve 3 and 4 . It is evident from figure 5 that the dihydroxy species is predominant. However in figure 6 , demonstrating the distribution curve for DOT (IV) - 1,10-phenanthroline system, monohydroxy species is also significant but the dihydroxy species is highest in percentage (90\%).

$0 \leq a \leq 2$ 


\section{International Journal of Science and Research (IJSR) \\ ISSN (Online): 2319-7064}

Index Copernicus Value (2013): 6.14 | Impact Factor (2014): 5.611

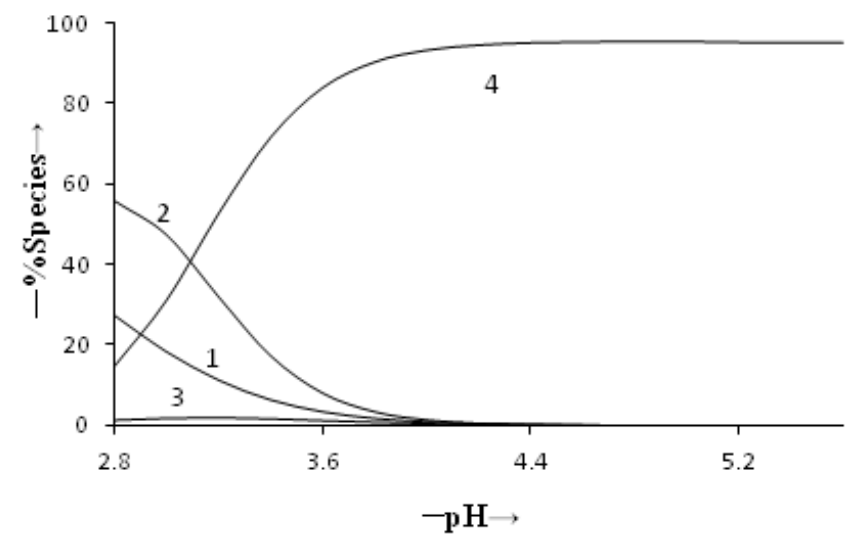

Figure 3: Speciation Curves for DMT(IV)-2,2'-Bipyridyl

(1:1) System at $30 \pm 1{ }^{\circ} \mathrm{C}\left[\mu=0.10 \mathrm{M}\left(\mathrm{NaNO}_{3}\right)\right]$

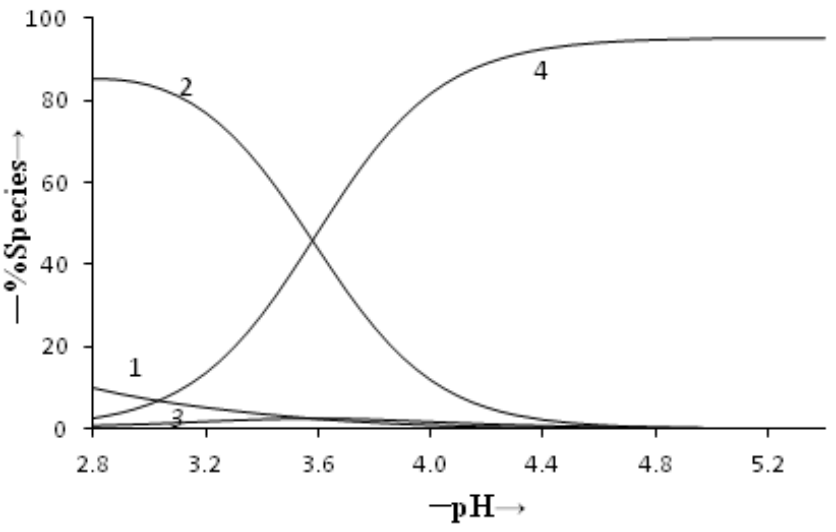

Figure 4: Speciation Curves for DOT(IV)-2,2'-Bipyridyl

(1:1) System at $30 \pm 1^{\circ} \mathrm{C}\left[\mu=0.10 \mathrm{M}\left(\mathrm{NaNO}_{3}\right)\right]$

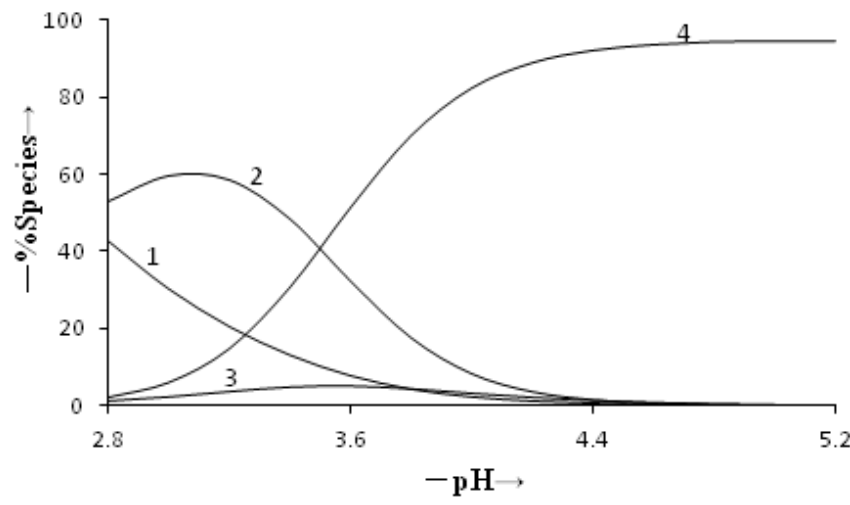

Figure 5: Speciation Curves for DMT(IV)-1,10

Phenanthroline (1:1) System at $30 \pm 1{ }^{\circ} \mathrm{C}\left[\mu=0.10 \mathrm{M}\left(\mathrm{NaNO}_{3}\right)\right]$

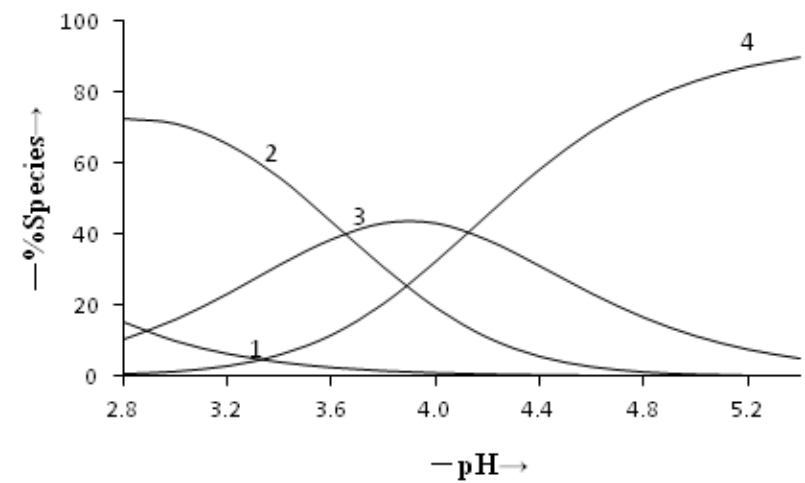

Figure 6: Speciation Curves for DOT(IV)-1,10

Phenanthroline (1:1) System at $30 \pm 1^{\circ} \mathrm{C}\left[\mu=0.10 \mathrm{M}\left(\mathrm{NaNO}_{3}\right)\right]$

Where 1. [M] 2. [ML] 3. [ML(OH)] 4.[ML(OH) $)_{2}$ (fig.3-6)

The values of thermodynamic stability constant $\log \mathrm{K}_{\mu \rightarrow 0}$, are used to determine the ligational standard free energy change $\left(\Delta \mathrm{G}^{\circ}\right)$ for the complexation reaction from Van't Hoff isotherm $\left(\Delta \mathrm{G}^{\circ}=-2.303 \mathrm{RT} \ln \mathrm{K}_{\mu \rightarrow 0}\right)$. By putting this in Gibb's Helmholtz equation $\left(\Delta \mathrm{G}^{\circ}=\Delta \mathrm{H}^{\circ}-\mathrm{T} \Delta \mathrm{S}^{\circ}\right)$ and this can be written as:

$$
\log \mathrm{K}_{\mu \rightarrow 0}=\frac{-\Delta \mathrm{H}^{\mathrm{s}}}{2.303 \mathrm{R}} \frac{1}{\mathrm{~T}}+\frac{\Delta \mathrm{S}^{\mathrm{s}}}{2.303 \mathrm{R}}
$$

The standard enthalpy change $\left(\Delta \mathrm{H}^{\circ}\right)$ and entropy change $\left(\Delta \mathrm{S}^{\circ}\right)$ have been determined by linear least square fit 1

method between $\log K_{\mu \rightarrow 0}$ and $\bar{T}$. In equation (4) Slope= $\frac{-\Delta \mathrm{H}^{3}}{2.303 \mathrm{R}}$ and intercept $=\frac{\Delta \mathrm{S}^{3}}{2.303 \mathrm{R}}$

\section{Conclusion}

It is concluded from the observed facts that complexes formed with 2,2 '-bipyridyl show lower stability than those formed with 1,10-phenanthroline. This may be attributed to the difference in ring structure of two ligands. In 2,2'bipyridyl ring is separated by single bond which decrease its aromaticity and conjugation whereas in case of 1, 10phenanthroline three fused rings increases its aromaticity and conjugation.

On observing the values recorded in tables 1-3 it is observed that complex formation decreases with increasing ionic strength and increasing temperature. Thermodynamic parameters for various systems are recorded in tables 2 and 3. The negative values of $\Delta \mathrm{G}^{\circ}$ show that complex formations are energetically favourable. This is further supported by negative enthalpy and positive entropy values.

\section{Acknowledgement}

I am highly thankful to Prof. K. Dwivedi and Prof. S. K. Srivastav, Department of Chemistry, Jiwaji University (M.P.) and Prof. Renu Nair (Ahuja), V.R.G. Girls P.G. College Morar for his/her guidance. 


\section{International Journal of Science and Research (IJSR) \\ ISSN (Online): 2319-7064}

Index Copernicus Value (2013): 6.14 | Impact Factor (2014): 5.611

Table 1 : Protonation Constant of Ligands at different Temperatures \& Ionic Strengths

\begin{tabular}{|c|c|c|c|c|c|c|c|c|c|c|c|c|}
\hline \multirow{2}{*}{ Parameters } & \multicolumn{4}{|c|}{$20^{\circ} \mathrm{C}$} & \multicolumn{4}{|c|}{$30^{\circ} \mathrm{C}$} & \multicolumn{4}{|c|}{$40^{\circ} \mathrm{C}$} \\
\hline & $0.05 \mathrm{M}$ & $0.10 \mathrm{M}$ & $0.15 \mathrm{M}$ & $\mu \rightarrow 0$ & $0.05 \mathrm{M}$ & $0.10 \mathrm{M}$ & $0.15 \mathrm{M}$ & $\mu \rightarrow 0$ & $0.05 \mathrm{M}$ & $0.10 \mathrm{M}$ & $0.15 \mathrm{M}$ & $\boldsymbol{\mu} \rightarrow \mathbf{0}$ \\
\hline & \multicolumn{12}{|c|}{ 2,2'-Bipyridyl } \\
\hline $\log \beta_{\mathrm{HL}}$ & 4.32 & 4.22 & 4.20 & 4.58 & 4.16 & 4.14 & 4.02 & 4.30 & 4.00 & 3.84 & 3.70 & 4.20 \\
\hline \multirow[t]{2}{*}{$\log \beta_{\mathrm{H} 2 \mathrm{~L}}$} & 7.55 & 7.53 & 7.31 & 7.60 & 7.06 & 7.05 & 7.00 & 7.20 & 5.90 & 5.21 & 5.11 & 5.82 \\
\hline & \multicolumn{12}{|c|}{ 1,10-Phenanthroline } \\
\hline $\log \beta_{\mathrm{HL}}$ & 5.10 & 5.01 & 5.00 & 5.30 & 4.98 & 4.78 & 4.73 & 5.32 & 4.86 & 4.61 & 4.60 & 5.20 \\
\hline $\log \beta_{\mathrm{H} 2 \mathrm{~L}}$ & 8.79 & 8.56 & 8.30 & 9.50 & 7.54 & 7.25 & 6.00 & 8.37 & 5.74 & 5.55 & 5.40 & 6.22 \\
\hline
\end{tabular}

Table 2 : Thermodynamic Parameters of M (IV)- 2,2'-Bipyridyl Systems

\begin{tabular}{|c|c|c|c|c|c|c|c|c|}
\hline \multicolumn{9}{|c|}{ DMT(IV)- 2,2'-Bipyridyl System } \\
\hline \multirow[b]{2}{*}{ Parameter } & \multicolumn{2}{|c|}{$20^{\circ} \mathrm{C}$} & \multicolumn{2}{|c|}{$30^{\circ} \mathrm{C}$} & \multicolumn{2}{|c|}{$40^{\circ} \mathrm{C}$} & \multirow{2}{*}{$\begin{array}{c}-\Delta \mathbf{H}^{\mathbf{0}} \\
\mathbf{k J m o l}^{-1}\end{array}$} & \multirow{2}{*}{$\begin{array}{c}\Delta \mathbf{S}^{\mathbf{0}} \\
\mathrm{JK}^{-1} \mathrm{~mol}^{-1}\end{array}$} \\
\hline & $\log \mathrm{K}_{\mu \rightarrow 0}$ & $\begin{array}{c}-\Delta \mathbf{G}^{\mathbf{o}} \\
\mathbf{k J m o l}^{-1}\end{array}$ & $\log \mathrm{K}_{\mu \rightarrow 0}$ & $\begin{array}{c}-\Delta \mathbf{G}^{\mathbf{0}} \\
\mathbf{k J m o l}^{-1}\end{array}$ & $\log \mathrm{K}_{\mu \rightarrow 0}$ & $\begin{array}{c}-\Delta \mathbf{G}^{\mathbf{0}} \\
\mathbf{k J m o l}^{-1}\end{array}$ & & \\
\hline \multirow{3}{*}{$\begin{array}{l}\log \mathrm{K}_{\mathrm{ML}}^{\mathrm{M}} \\
\log \mathrm{K}_{\mathrm{ML}}^{\mathrm{ML}} \\
\log _{\mathrm{ML}(\mathrm{OH})}^{\mathrm{ML}(\mathrm{OH})}\end{array}$} & \multicolumn{2}{|c|}{5.1528 .89} & \multicolumn{2}{|l|}{5.0029 .00} & \multicolumn{2}{|l|}{4.9029 .37} & \multicolumn{2}{|c|}{23.9317 .10} \\
\hline & \multicolumn{2}{|l|}{7.7243 .31} & \multicolumn{2}{|l|}{7.7044 .67} & \multicolumn{2}{|l|}{7.4044 .35} & \multicolumn{2}{|c|}{30.6444 .55} \\
\hline & \multicolumn{2}{|c|}{11.0762 .10} & \multicolumn{2}{|c|}{11.0063 .81} & \multicolumn{2}{|c|}{10.6864 .00} & \multicolumn{2}{|c|}{37.3485 .81} \\
\hline \multicolumn{9}{|c|}{ DOT(IV)- 2,2'-Bipyridyl System } \\
\hline \multirow[b]{2}{*}{ Parameter } & \multicolumn{2}{|c|}{$20^{\circ} \mathrm{C}$} & \multicolumn{2}{|c|}{$30^{\circ} \mathrm{C}$} & \multicolumn{2}{|c|}{$40^{\circ} \mathrm{C}$} & \multirow{2}{*}{$\begin{array}{c}-\Delta \mathbf{H}^{\mathbf{0}} \\
\mathbf{k J m o l}^{-1}\end{array}$} & \multirow{2}{*}{$\begin{array}{c}\Delta \mathbf{S}^{\mathbf{0}} \\
\mathrm{JK}^{-1} \mathrm{~mol}^{-1}\end{array}$} \\
\hline & $\log K_{\mu \rightarrow 0}$ & $\begin{array}{c}-\Delta \mathbf{G}^{\mathbf{o}} \\
\mathbf{k J m o l}^{-1}\end{array}$ & $\log \mathrm{K}_{\mu \rightarrow 0}$ & $\begin{array}{c}-\Delta \mathbf{G}^{\mathbf{0}} \\
\mathbf{k J m o l}^{-1}\end{array}$ & $\log \mathrm{K}_{\mu \rightarrow 0}$ & $\begin{array}{c}-\Delta \mathbf{G}^{\mathbf{o}} \\
\mathbf{k J m o l}^{-1}\end{array}$ & & \\
\hline \multirow{3}{*}{$\begin{array}{l}\log \mathrm{K}_{\mathrm{ML}}^{\mathrm{M}} \\
\log \mathrm{K}_{\mathrm{ML}}^{\mathrm{ML}(\mathrm{OH})} \\
\log \mathrm{K}_{\mathrm{ML}(\mathrm{OH}) 2}^{\mathrm{MLH}}\end{array}$} & \multicolumn{2}{|l|}{6.9038 .71} & \multicolumn{2}{|l|}{6.6038 .29} & \multicolumn{2}{|l|}{6.5539 .25} & \multicolumn{2}{|c|}{33.5117 .39} \\
\hline & \multicolumn{2}{|l|}{9.1551 .33} & \multicolumn{2}{|l|}{9.1052 .79} & \multicolumn{2}{|l|}{9.0954 .48} & \multicolumn{2}{|c|}{5.74155 .54} \\
\hline & \multicolumn{2}{|c|}{12.3569 .28} & \multicolumn{2}{|c|}{12.3071 .36} & \multicolumn{2}{|c|}{11.8070 .72} & 52.6558 & \\
\hline
\end{tabular}

Table 3 : Thermodynamic Parameters of M (IV)-1,10-Phenanthroline Systems

\begin{tabular}{|c|c|c|c|c|c|c|c|c|}
\hline \multicolumn{9}{|c|}{ DMT(IV)-1,10-Phenanthroline System } \\
\hline \multirow[b]{2}{*}{ Parameter } & \multicolumn{2}{|c|}{$20^{\circ} \mathrm{C}$} & \multicolumn{2}{|c|}{$30^{\circ} \mathrm{C}$} & \multicolumn{2}{|c|}{$40^{\circ} \mathrm{C}$} & \multirow[b]{2}{*}{$\begin{array}{c}-\Delta \mathbf{H}^{\mathbf{0}} \\
\mathbf{k J m o l}^{-1}\end{array}$} & \multirow[b]{2}{*}{$\begin{array}{c}\Delta S^{\mathbf{o}} \\
\mathrm{JK}^{-1} \mathrm{~mol}^{-1}\end{array}$} \\
\hline & $\log \mathrm{K}_{\mu \rightarrow 0}$ & $\begin{array}{c}-\Delta \mathbf{G}^{\mathbf{0}} \\
\mathbf{k J m o l}^{-1}\end{array}$ & lo $\mathrm{g} \mathrm{K}_{\mu \rightarrow 0}$ & $\begin{array}{c}-\Delta \mathbf{G}^{\mathbf{0}} \\
\mathrm{kJmol}^{-1}\end{array}$ & $\log \mathrm{K}_{\mu \rightarrow 0}$ & $\begin{array}{c}-\Delta G^{\mathbf{0}} \\
\mathbf{k J m o l}^{-1}\end{array}$ & & \\
\hline \multirow{3}{*}{$\begin{array}{l}\log \mathrm{K}_{\mathrm{ML}}^{\mathrm{MI}} \\
\left.\log \mathrm{K}_{\mathrm{ML}}^{\mathrm{ML}} \mathrm{OH}\right) \\
\log \mathrm{K}_{\mathrm{ML}(\mathrm{OH}) 2}^{\mathrm{ML}(\mathrm{OH})}\end{array}$} & \multicolumn{2}{|l|}{6.5836 .91} & \multicolumn{2}{|l|}{6.5029 .00} & \multicolumn{2}{|l|}{6.4829 .37} & \multicolumn{2}{|c|}{9.5793 .25} \\
\hline & \multicolumn{2}{|l|}{8.8049 .37} & \multicolumn{2}{|l|}{8.7844 .67} & \multicolumn{2}{|l|}{8.7244 .35} & \multicolumn{2}{|c|}{7.66142 .58} \\
\hline & \multicolumn{2}{|l|}{12.1067 .88} & \multicolumn{2}{|c|}{11.9563 .81} & \multicolumn{2}{|c|}{11.9364 .00} & \multicolumn{2}{|c|}{16.28175 .93} \\
\hline \multicolumn{9}{|c|}{ DOT(IV)- 1,10-Phenanthroline System } \\
\hline \multirow[b]{2}{*}{ Parameter } & \multicolumn{2}{|c|}{$20^{\circ} \mathrm{C}$} & \multicolumn{2}{|c|}{$30^{\circ} \mathrm{C}$} & \multicolumn{2}{|c|}{$40^{\circ} \mathrm{C}$} & \multirow{2}{*}{$\begin{array}{c}-\Delta \mathbf{H}^{\mathbf{0}} \\
\mathbf{k J m o l}^{-1}\end{array}$} & \multirow[b]{2}{*}{$\begin{array}{c}\Delta \mathbf{S}^{\mathbf{0}} \\
\mathrm{JK}^{-1} \mathrm{~mol}^{-1}\end{array}$} \\
\hline & $\log \mathrm{K}_{\mu \rightarrow 0}$ & $\begin{array}{c}-\Delta \mathbf{G}^{\mathbf{0}} \\
\mathbf{k J m o l}^{-1}\end{array}$ & $\log \mathrm{g}_{\mu \rightarrow 0}$ & $\begin{array}{c}-\Delta \mathbf{G}^{\mathbf{0}} \\
\mathrm{kJmol}^{-1}\end{array}$ & $\log \mathrm{K}_{\mu \rightarrow 0}$ & $\begin{array}{c}-\Delta G^{\mathbf{0}} \\
\mathbf{k J m o l}^{-1}\end{array}$ & & \\
\hline \multirow{3}{*}{$\begin{array}{l}\log \mathrm{K}_{\mathrm{ML}}^{\mathrm{MI}} \\
\log \mathrm{K}_{\mathrm{ML}}^{\mathrm{ML}}(\mathrm{OH}) \\
\log \mathrm{K}_{\mathrm{ML}(\mathrm{OH}) 2}^{\mathrm{ML})}\end{array}$} & \multicolumn{2}{|l|}{6.5036 .47} & \multicolumn{2}{|l|}{6.4837 .59} & \multicolumn{2}{|l|}{6.4538 .66} & \multicolumn{2}{|c|}{4.79108 .21} \\
\hline & \multicolumn{2}{|l|}{10.1056 .66} & \multicolumn{2}{|l|}{9.9857 .44} & \multicolumn{2}{|c|}{10.0260 .05} & \multicolumn{2}{|c|}{7.66166 .84} \\
\hline & \multicolumn{2}{|l|}{12.6070 .69} & \multicolumn{2}{|c|}{12.5973 .04} & \multicolumn{2}{|c|}{12.5074 .91} & 9.57208 & \\
\hline
\end{tabular}

\section{References}

[1] P.Paliwal, and S.K. Srivastava, Int. J. Adv. Res., 3(12), 1434-1439, 2015.

[2] B.Z. Momeni, R. Kia and S. Ghanbarzadeh, Monatshefte fur Chemie, 2012.
[3] T. Mancilla, L. Carrillo, L.S.Z. Rivera, C.C. Camacho, D. De Vos, R. Kiss, F. Darro, B. Mahieu, E.R.T. Tiekink, H. Rahier, M. Gielen, M. Kemmer, M. Biesemans and R. Willem, Appl. Organometal. Chem. 15, 593-603, 2001.

[4] Qingshan Li, Pin Yang, Hongfei Wang and Maolin Guo, J. Inorg. Biochem., 64, 181-195, 1996. 
[5] L. Nagy, A. Szorcsik and K. Kovacs, Pharm. Hungarica, 70, 53-71, 2000.

[6] A.K. Saxena and F. Huber, Coord. Chem. Rev., 95, 109, 1989.

[7] P.G. Sammes and G. Yahioglu, Chem. Soc. Rev., 327, 1994.

[8] A. Bengtson, N.K. Goh, A. Hazell, L.E. Khoo, J. Ouyang and K.R. Pedersen, Acta Chem. Scand., 50, 1020, 1996

[9] Liang-Fu Tang, Zhi-Hong Wang, Wen-Li Jia, Yu-Ming $\mathrm{Xu}$ and Ji-Tao Wang, Polyhedron, 19, 381-387, 2000.

[10] P. Alvarez-Boo, J.S. Casas, A. Castineiras, M.D. Couce, E. Freijanes, Furlani, U. Russo, V. Scarcia, J. Sordo and M. Varela, Inorg. Chim. Acta, 353, 8-14, 2003.

[11]C. Pettinari, F. Marchetti and A. Cingolani, Polyhedron, 15, 1263-1276, 1996.

[12] C. Pettinari, F. Marchetti, M. Pellei, A. Cingolani, L. Barba and A. Cassetta, J. Organomet. Chem., 515, 119130, 1996 .

[13]C. Pettinari, M. Pellei, F. Marchetti, C. Santini and M. Miliani, Polyhedron,17(4), 561-576, 1998.

[14] C. Pettinari, M. Pellei, C. Santini, I. Natali, F. Accorroni and A. Lorenzotti, Polyhedron, 17, 4487-4496, 1998.

[15]C. Pettinari, M. Pellei, M. Miliani, A. Cingolani, A. Cassetta, L. Barba, A. Pifferi and E. Rivarola, J. Organomet. Chem., 553, 345-369, 1998.

[16] C. Pettinari, Main Group Met. Chem., 22(11), 661-692, 1999.

[17] Sen-ichi Aizawa, T. Natsume, K. Hatano and S. Funahashi, Inorg. Chim. Acta, 248, 215-224, 1996.

[18] A. Zabardasti, A. Kakanejadifard and L. Shabani, Bull. Chem. Soc. Ethiop., 21(1), 85-94, 2012.

[19] B. Gleeson, J. Claffey, D. Ertler, M. Hogan, H.M. Bunz, F. Paradisi, D. Wallis and M. Tacke, Polyhedron, 27, 3619, 2008.

[20] A.J. Crowe, in: B.K. Kepler (Ed.), Metal Complexes in Cancer Chemotherapy, VCH, Weinheim, (1993).

[21]L.G. Sillen and A.E. Martell, J. Bjerrum, Stability Constants of Metal-ion Complexes, Vol.1, Ed. 2, Special Publication, No. 17, The Chemical Society, London 1971.

[22] S. Chaberek and A.E. Martell, J.Am.Chem.Soc., 74, 5052, 1952.

[23] S. Chaberek and A.E. Martell, J.Am.Chem.Soc., 77, 1477, 1955.

[24]R. Nayan and A.K. Dey, Indian J.Chem., 14-A , 892, 1976.

[25]R. Nayan and A.K. Dey, Transition Met. Chem.,1, 61, 1976.

[26] R. Nayan and A.K. Dey, J.Inorg.Nucl.Chem., 36, 2545, 1974.

[27] M. Chandra, Transition Met.Chem., 8, 276-279, 1983.

[28]I.G. Sayce, Talanta, 15, 1397, 1968.

[29] I.G. Sayce, Talanta, 18, 653, 1971.

[30]I.G. Sayce and V.S. Sharma, Talanta, 19, 831, 1972. 